\title{
"La gran grieta del mundo". Siegfried Kracauer, Walter Benjamin y los debates sobre la figura del intelectual
}

\author{
["The great Rift of the World". Siegfried Kracauer, Walter Benjamin and the Debates \\ about the Figure of the Intellectual]
}

Miguel Vedda ${ }^{1}$

\begin{abstract}
The article examines a set of works of Siegfried Kracauer and Walter Benjamin with the intention of reconstructing the contributions of both authors to a critical theory of the intellectuals. Placed between the fronts, both essayists tried to bring together the social and political commitment and the search of a politicization of the intellectuals with the reluctance to accept and reproduce the dictations of an dogmatic party organization. Term of comparison for the context of production of both authors is considered the Paris of the Restaurationszeit, in which a group of exiled German thinkers and writers constituted themselves as the first modern intellectuals, identified with the figure of the lacerated consciousness (zerrissenes Bewußtsein), as it was formulated by Hegel.
\end{abstract}

Keywords: intelectual; lacerated consciousness; essay; satire; exile

Resumen: El artículo examina un conjunto de obras de Siegfried Kracauer y Walter Benjamin con el propósito de reconstruir los aportes de ambos autores a una teoría crítica de los intelectuales. Situados entre los frentes, los dos ensayistas intentaron conjugar el compromiso social y político y la búsqueda de una politización de los intelectuales con la renuencia a aceptar y reproducir los dictados de una organización partidaria dogmática. Como término de comparación para el contexto de producción de ambos autores se considera el París de la Restauración, en el que un grupo de pensadores y escritores alemanes exiliados se constituyeron como los primeros intelectuales modernos, identificados con la figura de la conciencia desgarrada (zerrissenes Bewußtsein), tal como fue formulada por Hegel.

Palabras clave: intelectual; conciencia desgarrada; ensayo; sátira; exilio

\footnotetext{
${ }^{1}$ Professor do Instituto de Filología Hispánica da Universidad de Buenos Aires.

Email: miguelvedda@yahoo.com.ar
} 
Vedda, Miguel. -"La gran grieta del mundo".

Es conocido el hecho de que Siegfried Kracauer y Walter Benjamin dedicaron arduos esfuerzos a mostrar las correlaciones existentes entre, por un lado, el París de la Monarquía de Julio, la Segunda República y el Segundo Imperio y, por otro, el contexto europeo de entreguerras. Los principales resultados de esa exploración pueden verse, en el caso de Benjamin, en los trabajos sobre Baudelaire y en el ingente material sobre los Pasajes parisinos; en el de Kracauer, en la "biografía social” sobre Jacques Offenbach und das Paris seiner Zeit (1937). Las similitudes y diferencias entre ambas indagaciones acerca del París de la Restauración, entendido como prehistoria del contexto de comienzos del siglo $\mathrm{XX}$ - signado por la guerra mundial, la crisis económica y el ascenso del nazismo - fueron explicitadas en diversas ocasiones (Cf., p. ej., AGARD 2001: 187191; Machado 2008: 95-105; Agard 2010: 210-218). Pero no se destacó, en cambio, hasta cuál punto pudo haber sido decisiva, en la elección de los dos ensayistas alemanes, la conciencia de que en la capital del siglo XIX había surgido por primera vez un modelo de intelectual acorde con las condiciones críticas y cambiantes de la Modernidad, y al que responden tanto el autor de Die Angestellten como el de Einbahnstraße. El primer trazado de ese modelo se encuentra en Heine, cuyo Ludwig Börne (1840) es una de las primeras y más audaces tentativas para definir las peculiaridades y la función del intelectual moderno. A propósito de la disputa entre Börne y Heine escribió Hans Magnus Enzensberger (1989: 385) que ella representa "posiblemente, la controversia más rica en consecuencias de la literatura alemana. La discusión en torno a ella lleva ciento cincuenta años, y no se avizora un final". ${ }^{2}$ Nuestra intención es, en este estudio, extraer, en primer lugar, las propuestas de Heine del curso de la historia, y establecer con ellas una constelación que nos permita arrojar mejor luz sobre las reflexiones de Kracauer y Benjamin en torno al intelectual, y sobre la vigencia de este último.

En el marco de las polémicas con el ensayista y jacobino intempestivo Ludwig Börne, Heine manifestó su convicción en que la única opción razonable para el intelectual moderno no podría ser la afiliación a una Weltanschauung doctrinaria que habría ya

\footnotetext{
2 "Der Streit zwischen Börne und Heine ist wahrscheinlich die folgenreichste Kontroverse der deutschen Literatur. Die Diskussion darüber dauert seit hundertfünfzig Jahren an, und ein Ende ist nicht abzusehen”.
} 
Vedda, Miguel. -"La gran grieta del mundo".

resuelto resolver todos los problemas teóricos y que debería, por lo tanto, ser solo difundida y aplicada por sus partidarios, sino a una práctica exploratoria para la cual no existen caminos ni metas fijados de antemano. Ubicado entre los frentes, el intelectual no encuentra un lugar de refugio ni en el repliegue esteticista, ni en la comodidad que le brinda una doctrina política, sino en una búsqueda despojada de certezas que representa su único compromiso genuino con los condenados de la tierra. El desgarramiento propio de la Modernidad exige de los intelectuales el abandono de las seguridades dogmáticas y la incertidumbre propia de las conciencias desgarradas. En los Reisebilder (18261831), aludió Heine a la significación de esta homología entre la fragmentación del mundo y la fragmentación interna del ánimo del escritor:

\begin{abstract}
Ah, querido lector, si quieres lamentarte por aquel desgarramiento, laméntate antes bien de que el propio mundo esté escindido. Pues como el corazón del poeta es el centro del mundo, dicho corazón tenía que hallarse lastimosamente desgarrado en la época actual. Aquel que se jacte de haber mantenido entero su corazón, debe confesar que posee un corazón prosaico [...]. A través del mío, en cambio, pasa la gran grieta del mundo, y justamente por ello sé que los grandes dioses me han honrado por encima de muchos otros, y me han considerado digno del martirio poético (HEINE 1975: II, 405). ${ }^{3}$
\end{abstract}

Una actitud tal permitió al "desgarrado" Heine convertirse en modelo inicial de una figura central para la Modernidad: la del intelectual crítico. Se sabe que Sartre identificó, como hora de nacimiento del intelectual moderno, el último tercio del siglo XIX, en el marco de la agitación producida en torno al affaire Dreyfus; pero con acierto destacó Gerhard HöHN (1991: 67) que "antes de que existieran “les intellectuels”, existían ya intelectuales individuales", 4 y que ya el París de la Restauración había ofrecido un terreno propicio para que ellos aflorasen. ${ }^{5}$ El hecho de que, según Sartre, el desgarramiento

\footnotetext{
3 “Ach, teurer Leser, wenn du über jene Zerrissenheit klagen willst, so beklage lieber, daß die Welt selbst mitten entzweigerissen ist. Denn da das Herz des Dichters der Mittelpunkt der Welt ist, so mußte es wohl in jetziger Zeit jämmerlich zerrissen werden. Wer von seinem Herzen rühmt, es sei ganz geblieben, der gesteht nur, daß er ein prosaisches, weitabgelegenes Winkelherz hat. Durch das meinige ging aber der große Weltriß, und eben deswegen weiß ich, daß die großen Götter mich vor vielen anderen hoch begnadigt und des Dichtermärtyrtums würdig geachtet haben".

4 "Bevor sich "les intellectuels" manifestierten, existierten schon einzelne Intellektuelle".

5 "Sin realizar un cambio de lugar, pero con un desplazamiento cronológico claro, es posible considerar el París de 1832, y no recién el París de 1898, como el lugar de nacimiento del intelectual moderno, con la contestation permanente de la vieja sociedad alemana y con la crítica radical a la sociedad francesa moderna -con, en suma, el Prefacio y las Circunstancias francesas- como partida de nacimiento" ("Ohne ein Ortswechsel vornehmen zu müssen, aber mit einer deutlichen chronologischen Verschiebung kann man deshalb Paris 1832 und nicht erst Paris 1898 als die eigentliche Geburtsstunde des modernen
} 
Vedda, Miguel. -"La gran grieta del mundo".

(déchirure) sea un rasgo decisivo del intelectual no hace otra cosa que avalar la propuesta de Höhn; sobre todo si se piensa hasta qué punto se sintió desgarrado Heine entre el riguroso cultivo del oficio de escritor y la necesidad de rebasar los límites del propio métier para comprometerse con la realidad de su tiempo; es sugestivo que Heine no solo haya sido blanco de la ofensiva conservadora a raíz de su radicalismo político, sino además cuestionado por revolucionarios que encontraban inadmisible su respeto por la perfección artística. Pero Heine también ha sido hostigado por no colocar su crítica al servicio de un partido y por preservar su autonomía en cuanto intelectual independiente. ${ }^{6}$ Heine anticipó uno de los dilemas que habría de enfrentar el intelectual crítico a lo largo del siglo XX: la dificultad y la necesidad de mantener la posición lúcida del individuo independiente y de sostener, sin embargo, un compromiso inclaudicable con la realidad social. Heine encarna, pues, la tentativa de representar el papel del intelectual que se arriesga a llevar adelante sus exploraciones trazando sus propios derroteros y eludiendo los caminos transitados por los predecesores. No es azaroso que el poeta alemán cuestione el efecto paralizador que producen las ortodoxias; menos entusiasta que sus contemporáneos republicanos o conservadores, se siente atraído hacia el escepticismo; o, mejor aún, se ve arrastrado por un movimiento pendular que lo balancea entre la certeza y la duda, entre la acción y el pensamiento, entre el pathos y la sátira; cada uno de los extremos contribuye, dialécticamente, a relativizar los abusos a los que podría arrastrar el otro. Esta problemática aparece en el libro sobre Börne como una alternancia entre el flujo y el reflujo revolucionarios, o entre el fervor de la empatía y la frialdad de la distancia crítica. El talento para descubrir el aspecto satírico de la realidad ayuda a Heine a eludir la visión unilateral de los poetas de tendencia y de Börne que, en su esfuerzo por mantener una actitud invariablemente seria, caen en el ridículo. $\mathrm{Du} s u$ blime au ridicule il n'y a qu'un pas: ${ }^{7}$ esta máxima podría valer como advertencia frente

Intellektuellen ansehen - mit der 'contestation permanente' der alten deutschen und mit der radikalen Kritik der modernen französischen Gesellschaft, mit, kurz, der Vorrede und den Französischen Zuständen, als dokumentarischem Akt"; HöHN 1987: 31).

${ }^{6}$ Según Laube, Heine le habría hecho el siguiente comentario, en el curso de una conversación: "[...] ¡cómo puedes exigir [...] que debe renunciar al todo frente a tu saber partidario! No pertenezco a ningún partido, o tan solo - concluyó, riendo- a mi propio partido" ("wie kannst Du verlangen [...] daß ich das Alles aufgeben soll von Deiner Parteiweistheit! Ich gehöre zu keiner Partei, oder doch nur - schloß er lachend - zu meiner Partei”; apud ENZENSBERGER 1989: 109).

${ }^{7}$ De lo sublime a lo ridículo hay solo un paso: esta máxima fue enunciada por Napoleón durante la huida de Rusia en 1812; Heine la cita en Das Buch Le Grand y en Die romantische Schule. 
Vedda, Miguel. -"La gran grieta del mundo".

a la pretendida elevación trágica de los republicanos; pero la conciencia con la que ella se enlaza explica el rechazo de que fue objeto Heine, en la medida en que, como comenta Windfuhr, "Pathos y extremismo siempre fueron preferidos en Alemania frente al comportamiento irónicamente mitigado y reflexivo" (WINDFUHR 1969: 174). ${ }^{8}$ La combinación de aproximación y distancia pone a Heine a salvo del peligro de convertirse en doctrinario, y le permite reaccionar con sutileza frente a los más pequeños cambios en el paisaje social sin perder de vista los desarrollos subterráneos.

Una percepción semejante se encuentra ligada a un aprovechamiento de las posibilidades que ofrece la condición de exiliado; una condición que Heine supo transformar de necesidad en virtud. El exilio es un "doloroso goce" (Schmerzjübel) al que debe Heine su amplitud de visión; los panoramas acerca de Francia y Alemania que abren tanto el Börne como otros ensayos de Heine - baste con mencionar Deutsche Zustände (1833) y De l'Allemagne (1835) -, deben su originalidad al hecho de haber sido trazados por alguien que observa esos ámbitos desde un punto de vista a la vez interno y externo. El dinamismo de Heine pertenece a la sustancia misma de la forma ensayística; esta última ha asumido siempre como suya la función de captar los objetos en pleno movimiento. Persuadido de la transitoriedad de todo lo existente, Montaigne ha escrito: "No puedo asegurar mi objeto, porque se tambalea y turba como por embriaguez natural. Tómolo en el punto en que lo examino y no pinto su ser, sino el que me muestra al pasar [...]. Así, debo acomodar mi trabajo al momento, y no solo podré cambiar de fortuna, sino incluso de intención” (MONTAIGNE 1984, III: 19-20). La perpetua movilidad del sujeto y del objeto es premisa para el desarrollo de la exploración ensayística: "Si mi alma pudiera afirmar el pie, yo no seguiría ensayándome, pero siempre la tengo en aprendizaje y prueba" (ibíd.). Tres siglos después, Kracauer hizo, a propósito de Erasmo, una observación que alude a una observación que alude a su propia obra ensayística: "su aversión por las fórmulas y recetas, con sus contenidos solidificados, lo impulsó a mantener sus ideas, por decirlo de alguna manera, en estado fluido, ellas no cuajaron, y no podían hacerlo, en un programa institucionalizado" (KRACAUER 2010: 58). ${ }^{9}$ Situa-

\footnotetext{
8 "Pathos und Extremismus sind in Deutschland immer beliebter gewesen als ironisch gedämpftes und reflektiertes Verhalten".

9 "his aversion to formulas and recipes with their congealed contents prompted him to keephis ideas, so to speak, in a fluid state, they did not, and could not, jell into a institutionalized program" (KRACAUER 1995:
} 
Vedda, Miguel. -"La gran grieta del mundo".

do entre ambos, Heine sostiene una posición acorde con la de estos dos grandes ensayistas, en la medida en que, fascinado por la vitalidad del objeto, se rehúsa a inmovilizarlo dentro de un esquema dogmático.

\section{2}

"La grieta del mundo pasa también a través de mí" (ADORNO/KRACAUER 2008: 11) ${ }^{10}$ : esta paráfrasis de Heine que encontramos al final de una carta de Kracauer a Adorno fechada el 5 de abril de 1923, evidencia ya de por sí un rasgo que une al autor de Theory of Film con el poeta y ensayista de la Restauración. A semejanza de este, Kracauer presenta la imagen de un homo duplex en el que se advierte tanto un interés por impulsar una politización de los intelectuales (Benjamin), como en colocar la autonomía de pensamiento a salvo de todo entusiasmo utópico y, en particular, de todo sometimiento bajo un programa ideológico, ya fuera este el de un partido político, una teoría ortodoxa o una clique como la que representaba, a sus ojos, la Escuela de Frankfurt. Su vocación de extraterritorial - que lo indujo a decir, en carta a Leo Löwenthal, que la única existencia verdadera es la de los vagabundos - hacía de él una personalidad por completo incompatible con la inmovilidad de un sistema. La aversión por lo estacionario recorre su obra desde los primeros artículos - compuestos bajo la intensa influencia de Simmel -, hasta History. The Last Things before the Last, y permite entender la insistencia que, en este tratado póstumo, pone el pensador en destacar su temor frente a todo lo que ha sido fijado en forma definitiva, como también en testimoniar su honda afinidad con Erasmo, quien estaba sostenido por la convicción "de que la verdad deja de serlo en cuanto se convierte en dogma, y pierde así la ambigüedad que la distingue en cuanto verdad" (KRACAUER 2010: 57). ${ }^{11}$ No es azaroso que, al enfrentarse con los grandes movimientos ideológicos del pasado, Kracauer se haya interesado por el momento en que ellos se hallaban in statu nascendi, antes de su establecimiento e institucionalización definitivos. Esto es válido para su relación con el marxismo, en el que veía menos una doctrina capaz de ofrecer respuesta a todos los problemas sociales, que una perspectiva desde la

11).

10 "Der Riß der Welt geht auch durch mich".

11 "the truth ceases to be true as soon as it becomes a dogma" (KRACAUER 1995: 10). 
Vedda, Miguel. -"La gran grieta del mundo".

cual desenmascarar las ideologías, poniendo al descubierto la falsa conciencia que las sustenta. La singular combinación de responsabilidad política y escepticismo radical otorgó a Kracauer una identidad específica como "[i]ntelectual comprometido, marxista [...] sin por ello ser militante o respetuoso con ninguna ortodoxia. Kracauer era un 'intérprete' de la sociedad de su época que nunca ejerció ningún poder, excepto el de su inteligencia crítica; no era un 'intelectual orgánico' en el sentido gramsciano” (TRAVERSO 1998: 12). La preocupación por mantener viva a cualquier precio la lucidez crítica propugnó en Kracauer la fe en que el único modo en que el intelectual puede acceder a una visión original, no cosificada de la realidad sociohistórica consiste en observar a esta con una mirada extrañada, tal como solo podría dirigirla un outsider. De allí que la figura en la que debería encontrar su modelo el historiador materialista sea, según el autor de History, la del exiliado:

El verdadero modo de existencia del exiliado es el del extranjero. De manera que puede ver su existencia anterior con los ojos de alguien "que no es de la casa". Y así como es libre para salir de la cultura que le era propia, es lo suficientemente independiente para introducirse en la mentalidad del pueblo extranjero en cuyo seno está viviendo. Hay grandes historiadores que deben buena parte de su grandeza al hecho de que eran expatriados (KRACAUER 2010: 122). ${ }^{12}$

Como el otro judío de Frankfurt, Heine, entiende Kracauer que la extraterritorialidad representa tanto una perspectiva privilegiada para comprender el mundo burgués como una condición definitoria del sujeto moderno; es sugestivo que la ponderación de la mirada del exiliado preceda largamente a la emigración impuesta por el ascenso del nazismo. Ya los escritos tempranos se refieren a menudo a la existencia provisoria y errante a la que se ven condenados los habitantes de las grandes ciudades a partir de la disolución de las comunidades tradicionales: bajo el influjo del Lukács de Theorie des Romans destacó Kracauer la condición espiritualmente desamparada (geistig obdachlos), el desamparo ideal (ideelle Obdachlosigkeit) del hombre moderno. En tales circunstancias resulta ya un pernicioso anacronismo buscar un refugio nostálgico en la seguridad

\footnotetext{
12 "The exile's true mode of existence is that of the stranger. So he may look at his previous existence with the eyes of one 'who does not belong to the house'. Ans just as he is free to step outside the culture which was his own, he is sufficiently uncommitted to get inside the minds of the foreign people in whose midst he is living. There are grat historians who owe much of their greatness to the fact that they were expratriates" (KRACAUER 1995: 84).
} 
Vedda, Miguel. -"La gran grieta del mundo".

de las viejas cosmovisiones estables; un conservadurismo tal es tan estéril como el de aquellos artistas y escritores que se obstinan en seguir cultivando las viejas formas cerradas en medio de una realidad marcada por la provisoriedad y la apertura. La constatación de que la vida moderna se encuentra regida por un relativismo llevado al extremo, por efecto del cual los individuos "carecen de ataduras y de fundamento", de modo que "su espíritu flota a la deriva sin timón, en casa en todas partes y en ninguna" (KRACAUER 2006: 144), ${ }^{13}$ está en la base del modo en que Kracauer concibe al intelectual moderno. En vista de este imperativo de actualidad, ha podido decir con razón Dagmar Barnouw que si "Kracauer subrayó la importancia de un cuestionamiento más informado y autocrítico de la posición del intelectual en el espacio y el tiempo culturales, lo hizo a partir de su ocupación, sobre una base cotidiana, con la compleja actualidad temporal de una cultura moderna en movimiento" (BARNOUw 1994: 7). ${ }^{14}$ Desprovisto de certidumbres absolutas, el intelectual de la modernidad (tardía) solo puede responder a las exigencias que su tiempo le plantea manteniendo - como conciencia desgarrada - un permanente estado de atención sobre sí mismo: revisando permanentemente sus propias convicciones y, ante todo, interrogándose por su función y lugar dentro de la vida social. En un comentario polémico sobre Wissen und Verändern! de Döblin, Kracauer encuentra el real mérito del libro en "haber intervenido [...] en un debate que, entre nosotros, lleva hace tiempo una vida subterránea. Se trata, en dicho debate, de la determinación del lugar del estrato de la intelligentsia alemana. ¿A qué lugar pertenece, dónde se encuentra o no en casa?" (KRACAUER 1990: 2, 307). ${ }^{15}$ Más allá de que las propuestas positivas de Döblin le parezcan en todo punto inaceptables, opina el autor de la reseña que el libro ha conseguido, al menos, advertir que el lugar de los intelectuales se encuentra entre dos frentes. Ya sea que se hayan pasado a la reacción, que se hayan unido al movimiento obrero sacrificando sus convicciones, o que no sepan aún cuál es problema que se trata de dirimir, la mayoría de los intelectuales alemanes son refugiados

\footnotetext{
13 "Da diesen Menschen Haft und Grund fehlt, treibt ihr Geist steuerlos dahin, überall und nirgends zu Hause" (KRACAUER 1977: 108).

14 "Kracauer emphasized the importance of a more informed and self-critical questioning of the intellectual's position in cultural space and time, he did so out his concern, on a daily basis, with the complex temporal actuality of a modern culture in flux".

15 "Das Verdienst, von einem entschiedenden Punkt aus in eine Debatte eingegriffen zu haben, die bei uns seit langem unter der Oberfläche schwelt. Es geht in ihr um die Ortsbestimmung der deutschen Intelligenzschichte. Wohin gehört sie, wo ist sie zu Hause oder nicht zu Hause?’. El artículo de Kracauer en cuestión “Was soll Herr Hocke tun?", aparecido en la Frankfurter Zeitung el 17/4/1931.
} 
Vedda, Miguel. -"La gran grieta del mundo".

(Flüchtlinge) que no se muestran dispuestos a asumir todas las consecuencias de su situación.

Como en otros planos, en este la proposición de Kracauer es restringir el campo de elección a aquellas opciones que se encuentran a la altura de la realidad contemporánea, evitando las búsquedas de amparo en concepciones que el avance de la Modernidad ha vuelto obsoletas. Esto se asocia con el surgimiento de un nuevo tipo de escritor, que renuncia al aroma de eternidad que antes flotaba en torno a él y que, según Kracauer, ya huele a rancio; el escritor acorde con la época no se afana ya por meditar sobre lo absoluto, sino que ve su "misión en dar cuenta, para sí mismo (y para el gran público) de nuestra situación actual" (ibíd.: 344), ${ }^{16}$ aproximándose con ello a la función ocupada tradicionalmente por el periodista. Este desplazamiento, que una vez más presenta similitudes con las alteraciones en el sistema literario producidas durante el Vormärz en relación con el "cierre del período artístico" (HEINE), implica negar el "estrato trascendente del ser" por el que se dejaban embelesar los viejos idealistas y aproximarse voluntaria o involuntariamente - al materialismo dialéctico. Los nuevos escritores, "En lugar de comportarse en forma contemplativa, se comportan de manera política; en lugar de buscar lo universal por encima de lo particular, lo encuentran en la marcha de lo particular; en lugar de perseguir desarrollos, aspiran a producir rupturas" (ibíd.: 345). ${ }^{17}$ Pueden advertirse aquí hondas coincidencias con Benjamin: con un Benjamin que, a partir de 1924-25, fue deslizándose, en palabras de PALMIER (2006: 225), de la crítica esotérica a la publicística, pero que radicalizó aún más sus posiciones a partir de 1929, en el contexto de una colaboración cada vez más estrecha con Bertolt Brecht. Desde entonces, su concepción de la responsabilidad histórica del intelectual en tiempos de crisis fue afirmándose con creciente nitidez, a despecho de la perspectiva metafísica que prevalecía en los escritos tempranos. La crisis de la República de Weimar y el ascenso del nazismo hacen que, como Kracauer, Benjamin se preocupe cada vez más por indagar a fondo los presupuestos de su propia labor. El fallido proyecto, emprendido conjuntamente con Brecht, de editar la revista Krise und Kritik es en sí significativo, ya que al-

\footnotetext{
16 “[...] seine Aufgabe darin erblickt, sich (und dem großen Publikum) Rechenschaft abzulegen über unsere aktuelle Situation". La cita corresponde al artículo “Über den Schriftsteller", aparecido en Die Neue Rundschau en junio de 1931.

17 "Statt kontemplativ verhalten sie sich politisch; statt das Allgemeine über dem Besonderen zu suchen, finden sie es im Gang des Besonderen; statt Entwicklungen zu verfolgen, erstreben sie Abbrüche”.
} 
Vedda, Miguel. -"La gran grieta del mundo".

bergaba el propósito de impulsar una crítica que reformulase todo su campo de reflexión “en una crisis permanente; es decir, que concibiera la época como una 'época crítica', en el doble sentido" (BRECHT 1967: 18, 85-86). ${ }^{18}$ En Benjamin, la conciencia de vivir en una época crítica, era singularmente clara; de ahí que, desde fines de la década del veinte y comienzos de la del treinta, atravesasen sus ensayos como un hilo rojo, según señala Momme BRODERSEN (1990: 197), las "reflexiones sobre la posición social, la importancia y la tarea del intelectual"19. Le interesaba entonces encontrar respuesta a las preguntas por "dónde se sitúa el intelectual, qué papel e importancia le caben en la sociedad, qué tareas tiene que buscar para sí mismo" (ibíd.: 198) ${ }^{20}$. La búsqueda de un lugar para la intelligentsia implicaba tomar distancia tanto de los intelectuales que se autoproclamaban simplemente revolucionarios como de aquellos que trataban de hallar una ubicación cómoda dentro del orden burgués; a diferencia de ambos tipos, postula Benjamin la figura del intelectual "consciente de la crisis de su imagen y función, y que no se reconoce ya en los estereotipos" (PALMIER 2006: 599).

\section{3}

Ya en el artículo sobre el surrealismo se refería Benjamin a la crisis de la intelectualidad tradicional, asociada con una crisis del concepto humanista de libertad. Pero es en los escritos de 1933-34 donde aparecen más expresamente desarrolladas sus ideas sobre el carácter y función de los intelectuales. Como Kracauer, piensa Benjamin que la crisis ha contribuido a crear una situación en la que el intelectual ya no es posible actuar de manera espontánea, y en que tiene que examinar de manera consciente los presupuestos de su propia actividad; es sugestivo que, en "Der Autor als Produzent" (1933), se apoye en un pasaje de Brecht para advertir sobre las enormes consecuencias que ha de poseer, en artistas, escritores y críticos, la confusión por entonces dominante acerca de su situación. La alusión a Brecht no es anodina, en vista de que el propósito de Benjamin es inducir a los "trabajadores espirituales" a que asuman una distancia racionalmente crítica

\footnotetext{
18 “[ihr] ganzes Stoffgebiet in eine permanente Krisis umdenkt, also die Zeit als in zweifacher Bedeutung 'kritische Zeit' auffaßt'.

19 “Überlegungen über die gesellschaftliche Stellung, Bedeutung und Aufgabe des Intellektuellen".

20 "wo der Intellektuelle stehe, welche Rolle und Bedeutung ihm in der Gesellschaft noch zukomme, welche Aufgaben er sich selbst zu suchen habe".
} 
Vedda, Miguel. -"La gran grieta del mundo".

respecto de su propia producción: de cara a una situación crítica, no se trata de despertar en ellos la indignación, sino de volver extrañas - en consonancia con el programa del teatro épico - las circunstancias en las que viven. Si hoy “es más que nunca decisiva la representación que el escritor se hace de su trabajo" (GS II/2: 792), ${ }^{21}$ es comprensible que Benjamin encarezca a aquellos autores contemporáneos que se rehúsan a considerar su actividad como algo automático y obvio y que buscan el mayor grado de conciencia posible sobre los fundamentos de su producción. Es este el caso de Valéry, al que no en vano se ensalza abiertamente en el estudio "Zum gesellschaftlichen Standort des französischen Schriftstellers" (1933-4): en su voluntad de racionalizar la creación poética, el autor del Cementerio marino se halla, en el plano de la técnica, a la altura de una época que realizó avances inauditos en la racionalización de los procesos de producción material. Pero no ha logrado, en cambio, trasladar el concepto de planificación del ámbito de la obra de arte al de la comunidad humana: Valéry se detuvo en el umbral que habría rebasado Gide al solidarizarse con la causa del comunismo. Aquí se advierte que el propósito de Benjamin presenta a los artistas y pensadores ante un doble imperativo: por un lado, el de abandonar las formas y métodos del "viejo" mundo burgués, basados en la inspiración y en los viejos valores eternos de lo bello y lo bueno, para sustituirlos por la experimentación y el trabajo conscientes; por otro, el de rebasar el individualismo nihilista abrazando la causa del proletariado. En uno y otro caso, el propósito es sustraer al intelectual a aquel conformismo que está a punto de subyugarlo. Más discutible es la vinculación que percibe Benjamin entre ambos imperativos, explicitada al comienzo de "Der Autor als Produzent", donde se postula una afinidad entre tendencia política y calidad literaria:

[...] esta tendencia literaria, que está contenida implícita o explícitamente en toda tendencia política correcta... esto, y no otro, es lo que constituye la calidad de la obra. Por eso la tendencia política correcta de una obra incluye su calidad literaria, porque incluye su tendencia literaria (GS II/2: 685). ${ }^{22}$

\footnotetext{
21 "Heute ist mehr denn je die Vorstellung entscheidend, die sich der Schriftsteller von seiner Arbeit macht".

22 "diese literarische Tendenz, die implicit oder explicit in jeder richtigen politischen Tendenz enthalten ist - die und nichts anderes macht die Qualität des Werks. Darum also schließt die richtige politische Tendenz eines Werkes seine literarische Qualität ein, weil sie seine literarische Tendenz einschließt”.
} 
Vedda, Miguel. -"La gran grieta del mundo".

La afinidad aquí afirmada es, en nuestra opinión, problemática; como lo es en general la visión que Benjamin ofrece del medio literario soviético. Ejemplo de esto último lo ofrece el lugar asignado a Tretiakov, en quien se advierte el ejemplo más patente de dependencia funcional entre tendencia política correcta y técnica literaria progresista. La posición de Kracauer al respecto es menos entusiasta y, en esa medida, más realista; el hecho de que dedicara varios artículos a discutir los planteamientos de Tretiakov atestigua que les atribuía una relevancia innegable, aunque mantuviera frente a ellos unas reservas que expresa regularmente con circunspección. Así, en una reseña publicada en la Frankfurter Zeitung, admite Kracauer que el modelo del escritor "operativo" no es "el único tipo de escritor que hoy podría reclamar vigencia; pero posee con todo una importancia extraordinaria, y merecía también ser discutido públicamente en Alemania" (KRACAUER 1990: 3, 27). ${ }^{23}$ Indicador es que el autor de la reseña juzgue, a diferencia de Benjamin, que las ideas del escritor ruso eran del todo inaplicables en Alemania, de modo que su esencial contribución consistía solo en "incitar a algunos de nuestros literatos a pensar alguna vez de manera exhaustiva y precisa su relación con la praxis" (ibíd.: 28). ${ }^{24}$ Como en Döblin, también aquí se juzgan más importantes las críticas (directas o indirectas) que los enunciados positivos; en efecto, el libro de Tretiakov es para Kracauer un pretexto para atacar el idealismo del ambiente intelectual alemán:

Se describe la realidad concreta, en lugar de rastrear sus defectos de construcción; se busca una evasión en lo estético y se evita movilizar las fuerzas orientadas a la acción; se cultiva la metafísica, donde habría que ingresar a la economía, etc. [...] El libro de Tretiakov podría al menos llamar la atención de muchos autores sobre cómo habría que entender, en realidad, la áspera fusión de teoría y praxis (ibíd.). ${ }^{25}$

Escéptico se muestra Kracauer ante los efectos que podría tener una incondicional subordinación del intelectual a las demandas de la clase o el partido, en lo que debía de

\footnotetext{
23 "Er ist gewiß nicht [...] der einzige Schriftstellertypus, der heutige Gültigkeit zu beanspruchen hätte; aber er ist darum doch von einer außerordentlichen Wichtigkeit und verdiente auch in Deutschland öffentlich diskutiert zu werden". "Der 'operierende' Schriftsteller" apareció en la Frankfurter Zeitung el $17 / 2 / 1932$.

24 "manche unserer Literaten dazu anregen, ihr Verhältnis zur Praxis einmal genau zu durchdenken".

25 "Man beschreibt die Realität, statt ihren Konstruktionsfehlern auf die Spur zu kommen; man weicht ins Ästhetische aus und versäumt dabei, die aufs Handeln gerichteten Kräfte zu mobilisieren; man treibt Metaphysik, wo man in die Ökonomie hineinsteigen sollte usw. [...] Tretjakows Buch vermag viele Schreibende wenigstens darauf aufmerksam zu machen, was unter der bitter notwendigen Verschmelzung von Theorie und Praxis wirklich zu verstehen ist".
} 
Vedda, Miguel. -"La gran grieta del mundo".

ver una riesgosa instancia de sacrificium intellectus. En términos más claros y provocadores se expresan las propuestas de Kracauer en "Minimalforderung an die Intellektuellen" (1931), acaso el ensayo en el que aparecen mejor y más detalladamente expresadas las ideas de Kracauer sobre la función del intelectual y, en sí, un escrito que no ha recibido la suficiente atención. Expresa es aquí la determinación - como en Heine y en Benjamin - de arrancar a la intelectualidad revolucionaria de la instalación conformista en los aparatos doctrinarios heredados; lo que de ellos se exige es que "pongan radicalmente en duda todas las posiciones dadas. Es decir, deben confrontar sus conceptos heredados, y precisamente los que son en apariencia inconmovibles, con los resultados de la teoría revolucionaria, y luego dar cuenta sobre la realidad concreta que preservan aquellos conceptos" (KRACAUER 1994: 2, 354). ${ }^{26}$ La solidaridad genuina del intelectual con la causa del socialismo no estriba, pues, en la repetición de letanías, sino en una continua revisión de las herramientas de pensamiento, en vista de que la "afirmación rígida, adialéctica de los ideales socialistas enumerados degenera fácilmente en sabotaje del socialismo" y "los intelectuales que ceden ante lo dado, deponen sus armas ante una utopía" (ibíd.: 355). ${ }^{27}$ Estamos ante un programa que retoma, políticamente radicalizadas, alguna de las tesis ya formuladas en "das Ornament der Masse" (1927): lo que se reclama de los intelectuales es que apliquen sus armas al desmantelamiento de lo mitológico, a cuyo ámbito pertenecen todos los conceptos y opiniones fosilizados. El intelecto es definido aquí como un arma de destrucción de todo elemento mítico en el hombre y en torno a él; los pensadores y artistas que no se abocan a la sustancial tarea de desenmascarar las ideologías y poner a prueba todos los saberes recibidos, quedan atrapados en una irracionalidad natural.

Relevante es que Kracauer defina este trabajo desmitificador con una misión que debe ser asumida por los individuos. En el artículo "Über den Schriftsteller" (1931) se enunciaba esta convicción con más detalle, pero también con menos contundencia, en

\footnotetext{
26 "sie müssen ihre überkommenen Begriffe, und gerade die scheinbar unterschütterlichen, mit den Befunden der revolutionären Theorie konfrontieren und dann sich Rechenschaft darüber ablegen, welche Realität noch jenen Begriffen verbleibt". "Minimalforderung an die Intellektuellen" apareció en Die Neue Rundschau en julio de 1931.

27 "Die starre, undialektische Behauptung der aufgezählten sozialistischen Ideale entartet leicht zur Sabotage des Sozialismus, und Intellektuelle, die dem Vorgegebenen nachgeben, strecken ihre Waffen vor einer Utopie".
} 
Vedda, Miguel. -"La gran grieta del mundo".

buena medida para no realizar un ataque frontal al escritor soviético. En efecto, Kracauer sostiene aquí que, en un país como Alemania, no están dadas las condiciones para la directa incorporación del intelectual en el colectivo. La anarquía económica, la persistencia de ideologías vetustas y la frágil estructura de la intelligentsia hacen que, de momento, el escritor alemán mantenga una posición de aislamiento:

Solo como individuo (o, en el mejor de los casos, asociado con quienes piensan de manera similar) puede, por ahora, destruir la falsa conciencia, preparar una correcta y cumplir todas las otras funciones decisivas que le plantea la sociedad actual (ibíd.: 346 ). ${ }^{28}$

Es, sin embargo, ostensible (y así lo evidencia, por ejemplo, la correspondencia con Bloch) el escepticismo de Kracauer frente a cualquier subordinación del intelectual a las imposiciones de una organización colectiva. Entre las escasas coincidencias que encuentra entre sus posiciones y las de Döblin, se encuentra el ataque de este último contra el "colectivismo inmoderado" (überspitzer Kollektivismus) que "se conduce en forma antiindividualista muy por encima de la medida aconsejable. ¿Cómo habría de nacerle el ser humano que antes se ocupó de exterminar" (ibíd., 305). ${ }^{29}$ Aquí se roza un aspecto fundamental del pensamiento temprano de Kracauer: la reflexión sobre las alteraciones que produjo el capitalismo tardío en la personalidad humana. Con el pasaje del capitalismo liberal al monopólico, se tornó anacrónico el viejo concepto de individuo en el que se fundaba la ideología de la burguesía temprana. Pero, a diferencia de otros pensadores y artistas de comienzos del siglo XX, Kracauer cree que esas alteraciones hayan acarreado la muerte del individuo, sino que la emergencia de un nuevo concepto de persona, acorde con las nuevas condiciones sociales. Es característico que los principales lineamientos de este nuevo individuo aparezcan trazados en los ensayos estéticos y, sobre todo, en la novela Ginster. Von ihm selbst geschrieben. ${ }^{30}$

\footnotetext{
28 "Nur als einzelner (oder bestenfalls im Zusammenschluß mit Gleichgesinnten) kann er bis auf weiteres das falsche Bewußtsein zerstören, ein richtiges vorbereiten und alle anderen entscheidenden Funktionen erfüllen, die ihm in der gegenwärtigen Gesellschaft obliegen".

29 "der sich weit über das gebotene Maß hinaus antiindividualistisch gebärdet. Wie sollte ihm der Mensch entwachsen können, den er vorher ausgetilgt hat?"

${ }^{30}$ La redacción definitiva de la obra, en efecto, tuvo lugar entre 1927 y 1928, aunque existen esbozos anteriores.
} 
Vedda, Miguel. -"La gran grieta del mundo".

En la reseña que dedicó a Die Angestellten revela Benjamin hasta qué punto ha sabido captar atributos definitorios de este individualismo paradójico. En el autor del libro para quien desenmascarar es "una pasión"-, encuentra a alguien que penetra dialécticamente en sus temas no "en calidad de marxista ortodoxo, y aún menos de agitador práctico, sino por el hecho de que penetrar dialécticamente significa desenmascarar" (BENJAMIN 2008: 94). ${ }^{31} \mathrm{Al}$ margen de presentar, en este plano, ambivalencias mayores a las que se advierten en Kracauer, Benjamin se revela también escéptico ante las ventajas del sometimiento del intelectual bajo la disciplina partidaria. Es cierto que, frente a la aversión de Kracauer hacia el colectivismo, anhela Benjamin la muerte del individualismo, el desvanecimiento de la oposición entre vida pública y vida privada, la liquidación del intérieur burgués y su sustitución por una porosidad a la que había atribuido rasgos utópicos en el diario de viaje a Nápoles. Pero estos anhelos representan más un deseo utópico que un programa concreto de acción; y el Moskauer Tagebuch ${ }^{32}$ dejan entrever los recelos del ensayista alemán ante la política cultural soviética. Las posiciones más radicales a favor de una modificación de la intelligentsia en el sentido de una cosmovisión colectivista aparecen hacia 1930, en el marco de las discusiones vinculadas con el proyecto de Krise und Kritik; convencido de que los intelectuales no podrían asumir (como sí lo cree Brecht) el papel de líderes del proletariado, Benjamin llega a sostener que aquellos deberían ir a las fábricas y cumplir allí las funciones serviles que les asignen, en consonancia con las tesis de Tretiakov (cf. WIZISLA 2004: 143). Pero esto solo debería ocurrir después de la toma del poder por parte del proletariado, lo que delata las circunstancias históricas en que nació esta formulación: la expectativa de una revolución inminente en Alemania. Cuando estas esperanzas comenzaron a revelarse ilusorias, reasumió Benjamin la postura según la cual no había que "ver en él a un representante del materialismo dialéctico como un dogma, sino a un investigador al que la posición del materialismo le parece, en términos científicos y humanos, más fructífero,

\footnotetext{
31 "Und nicht als orthodoxer Marxist, noch weniger als praktischer Agitator, dringt er dialektisch ins Dasein der Angestellten, sondern weil dialektisch eindringen heißt: entlarven" (GS: III, 220).

${ }^{32}$ Compuesto por Benjamin durante su viaje a la ex Unión Soviética en 1926-1927; publicado por primera vez en 1980, después de la muerte de Asja Lacis.
} 
Vedda, Miguel. -"La gran grieta del mundo".

en todas las cuestiones que nos mueven, que la idealista" (GB: IV, 19). ${ }^{33}$ El elogio que Benjamin dedica a Gide como intelectual que se ha asociado al comunismo, pero sin convertirse en militante partidario, define también su propia ubicación. Como señala Palmier:

En una época en que los intelectuales eran tentados por el militantismo, él se mantuvo al margen de este. No piensa jamás en elaborar un programa de reflexiones políticas [...]. Colaborador de diarios y revistas, situado en el corazón de la actualidad, permaneció ajeno a las querellas ideológicas de la República de Weimar, no firmó ningún petitorio, ningún manifiesto (PALMIER 2006: 233).

Esta disposición se mantuvo durante los años del nazismo, en el curso de los cuales conservó el "papel de outsider que reivindicaba bajo la República de Weimar. [...] Benjamin no participó del trabajo de propaganda, del compromiso militante, rara vez publicó en las revistas del exilio" (ibíd.: 276). Más allá de su ocasional simpatía por Tretiakov, siguió siendo un marginal (Außenseiter), un trapero, para recurrir a las expresiones empleadas en la reseña de Die Angestellten. La marginalidad es justamente, como en Kracauer, la que ayuda a cimentar una disposición crítica - categoría, por cierto, emblemática en el conjunto de la obra de Benjamin - frente a la sociedad y frente al propio intelectual, sustrayendo a ambos del conformismo. Contrario a quienes sobrevaloraban el papel de la intelligentsia de cara a la clase obrera y a la época toda, el autor del Das Passagen-Werk se muestra también atravesado por la gran grieta del mundo. Podemos suscribir a la afirmación que hace Wizisla a propósito de Benjamin, Bloch y Brecht, aclarando que podríamos agregar a esta tríada el nombre de Kracauer:

Ellos no creían que el compromiso público pusiera en cuestión la autonomía del arte y la ciencia y, con ello, lesionara las capacidades creadoras, ni confundían la asunción de la influencia con la incorporación a un aparato de poder al que hubiera que sacrificar procedencia, pensamiento y acción creadora (WIZISLA 2004: 161-162). ${ }^{34}$

\footnotetext{
33 "Von solchen wäre mir der vertrauteste, in mir nicht einen Vertreter des dialektischen Materialismus als eines Dogmas, sondern einen Forscher zu sehen, dem die Haltung des Materialisten wissenschaftlich und menschlich in allen uns bewegenden Dingen fruchtbarer scheint als die idealistische" (carta a Marx Rychner del 7/3/1931).

34 "Weder glaubten sie, daß öffentliches Engagement die Autonomie von Kunst und Wissenschaft in Frage stelle und damit schöpferische Fähigkeiten beeinträchtige, noch verwechselten sie Einflußnahme mit Eingliederung in einen Machtapparat, dem Herkunft, Denken und schöpferishes Tun geopfert werden müsse".
} 
Vedda, Miguel. -"La gran grieta del mundo".

Convendría detenerse un poco más en el análisis de la conciencia desgarrada, a cuyo análisis se había entregado Heine, pero tras las huellas de Hegel, que había sido uno de sus maestros y referentes. Sabemos que, en la Phänomenologie des Geistes (1807), Hegel se apoya en un singular análisis de la novela El sobrino de Rameau ${ }^{35}$ para afirmar la esencial modernidad del desgarramiento de la conciencia. Según Hegel, la novela de Diderot se sustenta en una oposición entre dos modos de conciencia que pertenecen, en el fondo, a dos eras históricas. El narrador-filósofo es el alma noble (edelmütiges Bewußtsein), positiva e integrada a su sociedad, convencida de la justicia de las instituciones existentes, y orientada a aceptar las normas que las sustentan. Frente a él, el sobrino de Rameau es una conciencia desgarrada (zerrissenes Bewußtsein): cínica, inconstante y "vil" (niederträchtig) es, en todo caso, más congruente con los tiempos modernos que los defensores de una moralidad incorrupta. El bohemio es la figura representativa de un mundo en que la riqueza lo es todo, en que el espíritu se siente un peregrino en la tierra y en que tiene lugar la "absoluta y universal inversión y alienación de la realidad y del pensamiento" (HEGEL 1999, II: 282). 36 "El lenguaje del desgarramiento", afirma Hegel, “es [...] el lenguaje perfecto y el espíritu existente verdadero de todo este mundo de la formación" (ibíd.), ${ }^{37}$ en contraposición con el aparentemente noble y esencialmente vil lenguaje de la hipocresía. En su exégesis de la Phänomenologie, Jean Hyppolite comenta que, en este pasaje del tratado,

El bohemio devela la comedia que constituyen un mundo y un sistema social que han perdido su sustancialidad, y cuyos momentos no tienen ya estabilidad alguna. La conciencia de esta pérdida transforma la acción en comedia y la pura intención, en hipo-

\footnotetext{
${ }^{35}$ Los problemas textuales de la novela de Diderot son proverbiales: por temor a la censura, El sobrino Rameau (que Diderot, por idénticas razones, nunca publicó en vida) fue excluido de las primeras ediciones de obras completas. En 1804, Goethe lo tradujo al alemán a partir de una copia manuscrita hoy perdida; la traducción, publicada en 1805, fue traducida luego al francés por Saur, y añadida en un suplemento a las Oeuvres Complètes. Posteriormente aparecieron sucesivas ediciones, tomadas de un manuscrito proporcionado por la hija de Diderot, en el cual, sin embargo, las correcciones de los editores habían dañado el texto original. El texto arquetipo se halló en 1890, gracias a una feliz casualidad: Monval, un bibliotecario de la Comédie Française, descubrió en un negocio, pegada a un volumen de una colección de tragedias, una copia manuscrita de la novela, de la mano del propio Diderot. Prácticamente durante todo el siglo XIX, la novela fue conocida tan solo por la traducción goetheana, o por traducciones de esta traducción.

36 “"[...] absolute und allgemeine Verkehrung und Entfremdung der Wirklichkeit und des Gedankens".

37 "Die Sprache der Zerrissenheit aber ist die vollkommene Sprache und der wahre existirende Geist dieser ganzen Welt der Bildung".
} 
Vedda, Miguel. -"La gran grieta del mundo".

cresía. La ambición y el afán de dinero, la voluntad de volverse el amo del poder, son la verdad de esta comedia (HYPPOLITE 1946: 400-401).

La conciencia desgarrada habla sarcásticamente el lenguaje de la economía, mientras la conciencia noble sigue recurriendo al lenguaje de un anacrónico moralismo. A este modelo de la conciencia desgarrada se mantuvo tenazmente apegado Heine, a contrapelo de Börne y de los miembros de la Joven Alemania. En contra de la insistencia de estos en la construcción de una personalidad unitaria y sin fisuras, Heine parece alojar dentro de sí una multiplicidad de personalidades. Es un rasgo que caracterizaba ya paradójicamente - al sobrino de Rameau: la perpetua variabilidad hacía de este un hombre sin atributos, "sin carácter"; el bohemio poseía una notable variabilidad, que terminó repercutiendo sobre el propio personaje del filósofo:

[...] mi espíritu se agitaba entre dos movimientos contrarios y yo no sabía si daría libre curso a mis ganas de reír o al arrebato de la indignación. Yo sufría. Veinte veces una carcajada impidió que estallase mi ira; veinte veces la cólera que surgía en el fondo de mi corazón se terminó con una carcajada. Estaba confuso ante tanta sagacidad, tanta bajeza, ideas alternativamente tan justas y tan falsas, una perversidad tan general de sentimientos, una torpeza tan completa y una franqueza tan poco frecuente (DIDEROT 1992: $3)$.

La confluencia de la disposición satírica con la carencia de una unidad de carácter tipifica también la poética y el pensamiento filosófico-político de Brecht, quien por lo demás se mostró siempre fascinado por la obra diderotiana y se propuso fundar una "Sociedad Diderot". Estas observaciones revelan afinidades con Benjamin, quien también insistió sobre la necesidad de destruir el concepto burgués de carácter; según Dag ANDERSSON, central en la concepción del carácter destructivo es el hecho de que este "no crea ningún tipo nuevo de carácter. Quiere simplemente destruir la idea de "carácter"”; ya en "Schicksal und Charakter" (1919) critica Benjamin la idea de que el carácter sea el centro motor en una relación causal entre lo interno y lo externo" (ANDERSSON 2000: 166s). ${ }^{38}$ No menos relevante es el hecho de que Benjamin haya visto en Brecht una encarnación ejemplar del carácter destructivo, que, como se lee en una entrada de diario de

\footnotetext{
38 "Doch schafft der destruktive Charakter keinen neuen Charaktertyp. Er will die Vorstellung vom 'Charakter' überhaupt zerstören. Bereits in Schicksal und Charakter kritisiert Benjamin den Gedanken, $\mathrm{da} ß$ Charakter das sich bewegende Zentrum in einem Kausalverhältnis zwischen Innerem und Äußerem sei”.
} 
Vedda, Miguel. -"La gran grieta del mundo".

1938, siempre "vuelve a poner en cuestión lo recién alcanzado" (GS, VI: 538). ${ }^{39}$ El escepticismo frente al sujeto unitario y soberano de la novela burguesa convive en Benjamin con el entusiasmo ante el anonimato del señor Keuner, que no es un "carácter", sino “ninguno" (Keiner) y que, como el carácter destructivo, asume dentro de sí la situación histórica (cf. ANDERSSON 2000: 172, n. 28).

En una crítica similar del carácter se apoya Kracauer: en sus artículos y reseñas publicadas en la Frankfurter Zeitung, pero ante todo en Ginster. En el capítulo final de la novela, el protagonista goza de una existencia anónima y extraterritorial, como individuo difuminado en medio de la masa. Ginster exorciza allí el horror de los castillos de la vida burguesa, en los que ve simbolizado "el despotismo de los hombres que se petrifica en tales castillos, y todos los órdenes que niegan la miseria. Hay también, por lo demás, castillos del amor. Habría que demoler las construcciones: la mala belleza, el esplendor" (KRACAUER 2004: 252). ${ }^{40}$ Lo contrario de la clausura en el intérieur es la apertura de la zona del puerto, con cuya "porosidad" (BENJAMIN) se identifica Ginster: en el barrio portuario "nada se encuentra encapsulado, el terreno desnudo se extiende aquí en forma abierta" (ibíd.). ${ }^{41}$ Los puertos sobrevivirán a los castillos "que se sienten tan espléndidos y grandiosos" pero "no conocen la muerte" (ibíd.); ${ }^{42}$ de ahí que deban "desmoronarse, desintegrarse, hasta que ellos mismos se conviertan en inmundicia. No me sentiré satisfecho antes de que esto suceda" (ibíd.). ${ }^{43}$ Ginster es, como su autor, un arquitecto fascinado por la demolición que, junto con las fortalezas de la vida privada burguesa, quiere socavar también la solidez de sus presuntos valores atemporales; no en vano Benjamin ha visto en él a un trapero que recoge "los trapos discursivos y los jirones lingüísticos a fin de arrojarlos en su carro", dejando que "revoloteen de manera bur-

\footnotetext{
39 “der das kaum Erreichte wieder in Frage stelle".

40 "Er galt der Herrscherei der Menschen, die sich zu solchen Schlössern versteigt, und allen Ordnungen, die das Elend verleugnen. Es gibt übrigens auch Schlösser der Liebe. Abreißen sollte man die Bauten, die schlechte Schönheit, den Glanz, herunter damit".

41 "hier ist nichts eingekapselt, der nackte Grund liegt hier offen".

42 "die sich so herrlich und groß fühlen. Sie kennen den Tod nicht".

43 “zerfallen, auseinanderbröckeln müssen sie, bis sie selbst zu Dreck werden. Eher kann ich mich nicht zufrieden geben"
} 
Vedda, Miguel. -"La gran grieta del mundo".

lona, al viento matinal, uno u otro de estos desteñidos calicós: 'humanidad', 'interioridad', 'profundidad"' (BENJAMIN 2010: 100s). ${ }^{44}$

Auténtico carácter destructivo, el “desgarrado” Kracauer se empeñó en imponer a sus escritos la misión de desmantelar las edificaciones ideológicas burguesas, a la vez que los preconceptos e ideas recibidas por las que se orienta un movimiento revolucionario inmovilizado en la repetición de letanías. Sobre estas estructuras de pensamiento anquilosadas se dirige la sátira de Kracauer, que se inscribe en la misma tradición que Heine y Brecht, y que, en su determinación de llevar a cabo una crítica radical del lenguaje, tenía que despertar en Benjamin un interés comparable con el que había alentado en él la obra de un Karl Kraus. Esto nos devuelve al problema de la intelligentsia, que está en el centro de la segunda novela de Kracauer, Georg, escrita entre 1930 y 1934, y a la que podríamos definir como una suerte de sociología (literaria) de los intelectuales. Eje medular de la obra es la exposición satírica de los más variados discursos ideológicos vigentes en la República de Weimar; como señala Dirck Oschmann, "no hay prácticamente ningún lugar común ni consigna del discurso intelectual contemporáneo que no sean expresados y [...] 'reseñados' a menos una vez" (OCHMANN 1999: 245) ${ }^{45}$ en la novela. Esta ofrece una mezcla singular de novela de evolución (Entwicklungsroman) y novela social (Gesellschaftsroman); en cuanto a la segunda, muestra el proceso de descomposición de una sociedad republicana que oculta sus intereses egoístas mediante construcciones ideológicas hueras y una abundante fraseología. En lo que atañe al primer tipo novelístico, Georg se acerca a la variante de la novela de desilusión (Desillusionierungsroman), al mostrar que el deseo inicial del protagonista de ingresar a la vida pública desemboca menos en una integración eficaz del outsider que en una mayor conciencia, por parte de este, sobre la vaciedad y anacronismo de los sistemas de ideas vigentes. El propio Kracauer describió al héroe de su segunda novela como "una suerte de

\footnotetext{
44 „Einen Lumpensammler frühe im Morgengrauen, der mit seinem Stock die Redelumpen und Sprach fetzen aufsticht, um sie murrend und störrisch, ein wenig versoffen, in seinen Karren zu werfen, nicht ohne ab und zu einen oder den anderen dieser ausgeblichenen Kattune 'Menschentum', 'Innerlichkeit', 'Vertiefung' spöttisch im Morgenwinde flattern zu lassen. - Ein Lumpensammler, frühe - im Morgengrauen des Revolutionstages“" (GS, III: 225).

45 "es gibt förmlich keinen Gemeinplatz und kein Schlagwort der zeitgenössischen intellektuellen Diskurse, die nicht wenigstens einmal zur Sprache gebracht und [...] 'besprochen' würden”.
} 
Vedda, Miguel. -"La gran grieta del mundo".

Parsifal" (eine Art Parsifal) cuyos rasgos definitorios son "una gran ingenuidad y una sinceridad absoluta" (KRACAUER 2004: 603). ${ }^{46}$ Todos los personajes del libro

ponen al descubierto sus puntos débiles o su valor oculto al entrar en contacto con él; sin que el propio Georg necesite juzgarlos o evaluarlos, a través de la mera existencia del personaje - y no, por ejemplo, a través de reflexiones cualesquiera -, revela el grado de realidad que los otros poseen en cada caso. (Quizás la remisión a Charlot (Chaplin) o a Schweik ayude a comprender a mi héroe. Está conectado con estos personajes por el hecho de que en él reside la función de separar lo humano de lo inhumano, lo verdadero de lo falso) (ibíd.: 603s). ${ }^{47}$

Como redactor - a imagen y semejanza el propio Kracauer - de un diario burgués de izquierda, Georg se halla en un lugar privilegiado para percibir la inesencialidad de los grandes discursos sociales; pero se ve asistido también por la invalorable inseguridad de alguien que nunca se había sentido en casa, de todos modos, en sus palabras, que se le falsean en la boca, del mismo modo que las palabras se deshacían como setas en la boca del Lord Chandos de Hofmannsthal. La inseguridad para hablar y escribir, en la que se funda su escepticismo lingüístico, le ayuda al personaje a no aceptar las palabras sin cuestionarlas. Al final de la obra, Georg es expulsado del diario, sus expectativas iniciales de integración social fracasan, y vuelve a estar solo como un intelectual extraterritorial; pero al menos ha podido ejecutar, casi sin quererlo, su tarea de destrucción. Con ello ha sentado las bases para la construcción de una sociedad nueva y de una nueva subjetividad; por lo demás, en Kracauer, como en Benjamin, la dinámica destructora encierra ya dentro de sí un impulso constructor. El pensamiento de ambos parece sostenerse en aquella leyenda talmúdica según la cual el mismo día en que se produjo la destrucción el templo tuvo lugar el nacimiento del Mesías.

\footnotetext{
46 "eine große Naivität und eine unbedingte Aufrichtigkeit".

47 "Alle Figuren des Buches geben lediglich dadurch, daß sie mit ihm in Beziehung treten, ihre Blößen bzw. ihren verborgenen Wert preis; ohne daß Georg selber sie zu beurteilen oder einzutaxieren brauchte, Kraft seiner bloßen Existenz - nicht etwa durch irgendwelche Reflexionen - enthüllt er den Grad der Wirklichkeit, den die andern jeweils besitzen. (Vielleicht hilft der Hinweis auf Charlot (Chaplin) oder auf den Schweyk ein wenig zum Verstädnis meines Helden. Er ist diesen Gestalten zum mindesten darin verwandt, daß auch ihm die Funktion innewohnt, das Menschliche vom Unmenschlichen, das Wahre vom Unwahren zu scheiden).
} 
Vedda, Miguel. -"La gran grieta del mundo".

\section{Literaturverzeichnis}

AdORnO, Theodor W. I KraCAUER, Siegfried. Briefwechsel 1923-1966. "Der Riß der Welt geht auch durch mich". Public. del Theodor W. Adorno Archiv, ed. de Wolfgang Schopf. Frankfurt/M: Suhrkamp, 2008.

AGARD, Olivier. Jacques Offenbach ou l'archéologie de la modernité. In: PERIVOLAROPOULOU, Nia / DesPoIX, Philippe (eds.). Culture de masse et modernité. Siegfried Kracauer. Sociologue, critique, écrivain. París: Sciences de l'homme, 2001: 179-211.

. Kracauer. Le chiffonnier mélancolique. París: CNRS, 2010.

ANDERSSON, Dag T. Destruktion/Konstruktion. In: OPITZ, Michael / WizISLA, Erdmut (eds.), Benjamins Begriffe. 2 vols. Frankfurt/M: Suhrkamp 2000, vol. I: 147-185.

BARnouw, Dagmar. Critical Realism. History, Photography and the Works of Siegfried Kracauer. Baltimore y Londres: The Johnn Hopkins U.P., 1994.

BENJAMIN, Walter. Gesammelte Schriften [= GS]. Ed. por Rolf Tiedemann y Hermann Schweppenhäuser, con la colaboración de Theodor W. Adorno y Gershom Scholem. 7 vols. Frankfurt/M: Suhrkamp, 1972-1989.

. Gesammelte Briefe (= GB). Ed. por el Theodor Adorno Archiv. Ed. de Christoph Gödde y Henri Lonitz. 6 vols. Frankfurt/M: Suhrkamp, 1995-2000.

. "Sobre la politización de los intelectuales". In: KRACAUER, Siegfried, Los empleados. Trad., postfacio y notas de M. Vedda. Barcelona: Gedisa, 2008: 93-101.

BRECHT, Bertolt. "Entwurf zu einer Zeitschrift Kritische Blätter". In: -. Gesammelte Werke in 20 Bänden. Frankfurt/M, Suhrkamp, 1967, vol. 18: 85-86.

BRODERSEN, Momme. Spinne im eigenen Netz. Walter Benjamin: Leben und Werk. Bühl-Moos: Elster, 1990.

DIDEROT, Denis. El sobrino de Rameau. Jacques el fatalista. Introd. de Jacques Proust. Trads. de Margarita Estapé y María Fortunata Prieto Barral. Barcelona: Planeta, 1992.

ENZENSBERGER, Hans Magnus. "Editorische Notiz". In: - (ed.), Ludwig Börne und Heinrich Heine. Ein deutsches Zerwürfnis. Leipzig: Reclam, 1989.

Hegel, Georg Wilhelm Friedrich. Phänomenologie des Geistes. In: -. Hauptwerke in sechs Bänden. Ed. de Wolfgang Bonsiepen y Reinhard Heede. Darmstadt: WBG, 1999, v. II.

HEINE, Heinrich. Sämtliche Schriften. $3^{\mathrm{a}}$ ed. corregida y aumentada. Ed. de Klaus Briegleb. 6 vols. Múnich: Hanser, 1975.

HöHN, Gerhard. Heine-Handbuch. Zeit, Person, Werk. Stuttgart: Metzler, 1987.

. "Heinrich Heine und die Genealogie des modernen Intellektuellen". In: - (ed.). Heinrich Heine. Ästhetisch-politische Profile. Frankfurt/M: Suhrkamp, 1991: 66-84.

Hyppolite, Jean. Genèse et structure de la Phénoménologie de l'Esprit de Hegel. París: Aubier, 1946.

KraCaUer, Siegfried. Das Ornament der Masse. Essays. Postfacio de Karsten Witte. Frankfurt/M: Suhrkamp, 1977.

Schriften 5. Ed. de Karsten Witte. 3 vols. Ed. de Inka Mülder-Bach. Frankfurt/M: Suhrkamp, 1990.

History. The Last Things Before the Last. Completado después de la muerte del autor por Paul Oskar Kristeller. Princeton: Markus Wiener, 1995. 
Vedda, Miguel. -"La gran grieta del mundo".

Werke. Ed. de Inka Mülder-Bach e Ingrid Belke. Vol. 7: Romane und Erzählungen. Ed. por Inka Mülder-Bach con la colab. de Sabine Biebl. Frankfurt/M: Suhrkamp, 2004.

. Estética sin territorio. Edición y traducción: Vicente Jarque. Murcia: Colegio oficial de aparejadores y arquitectos técnicos de la región de Murcia, 2006: 141-156.

. Historia. Las últimas cosas antes de las últimas. Introd. de Miguel Vedda. Trad. de María Guadalupe Marando y Agustín D’Ambrosio. Buenos Aires: Las cuarenta, 2010.

MACHADO, Carlos Eduardo Jordão. "Notas sobre Siegfried Kracauer, Walter Benjamin y el París del Segundo Imperio: puntos de contacto". In: BUCHENHORST, Ralph / VEDDA, Miguel (eds.), Observaciones urbanas - Benjamin y las nuevas ciudades. Buenos Aires: Gorla, 2008: 95-105.

Montaigne, Michel de. Ensayos. Trad. de Juan G. de Luaces. Notas prologales de Emiliano M. Aguilera. 3 vols. Buenos Aires: Hyspamérica, 1984.

Oschmann, Dirk. Auszug aus der Innerlichkeit: das literarische Werk Siegfried Kracauers. Heidelberg: Winter, 1999.

PALMIER, Jean-Michel. Le chiffonnier, l'Ange et le Petit Bossu. Esthétique et politique chez Walter Benjamin. Ed. establecida, anotada y presentada por Florent Perrier. Prefacio de Marc Jimenez. París: Klincksieck, 2006.

TRAVERSO, Enzo. Siegfried Kracauer. Itinerario de un intelectual nómada. Trad. de Anna Montero Bosch. Valencia: Edicions Alfons El Magnànim, 1998.

WINDFUHR, Manfred, Heinrich Heine: Revolution und Reflexion. Stuttgart: Metzler und Poeschel, 1969.

WIZISLA, Erdmut, Benjamin und Brecht. Die Geschichte einer Freundschaft. Mit einer Chronik und den Gesprächsprotokollen des Zeitschriftenprojekts "Krise und Kritik". Frankfurt/M: Suhrkamp, 2004.

Recebido em: 13/04/2014

aceito em: 01/05/2014 